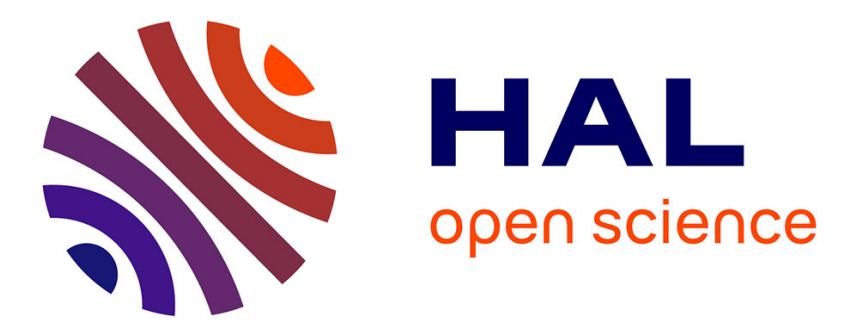

\title{
Experimental study of surface contributions to molecule formation in a recombining N2/O2 plasma
}

R a B Zijlmans, S Welzel, O Gabriel, G Yagci, J H van Helden, J Röpcke, D C Schram, R Engeln

\section{- To cite this version:}

R a B Zijlmans, S Welzel, O Gabriel, G Yagci, J H van Helden, et al.. Experimental study of surface contributions to molecule formation in a recombining N2/O2 plasma. Journal of Physics D: Applied Physics, 2010, 43 (11), pp.115204. 10.1088/0022-3727/43/11/115204 . hal-00569261

\section{HAL Id: hal-00569261 https://hal.science/hal-00569261}

Submitted on 24 Feb 2011

HAL is a multi-disciplinary open access archive for the deposit and dissemination of scientific research documents, whether they are published or not. The documents may come from teaching and research institutions in France or abroad, or from public or private research centers.
L'archive ouverte pluridisciplinaire HAL, est destinée au dépôt et à la diffusion de documents scientifiques de niveau recherche, publiés ou non, émanant des établissements d'enseignement et de recherche français ou étrangers, des laboratoires publics ou privés. 


\title{
Experimental study of surface contributions to molecule formation in a recombining $\mathrm{N}_{2} / \mathrm{O}_{2}$ plasma
}

\author{
R A B Zijlmans ${ }^{1}$, S Welzel $^{2}$, O Gabriel ${ }^{4}$, G Yagci $^{1}$, \\ J H van Helden ${ }^{3}$, J Röpcke ${ }^{2}$, D C Schram ${ }^{1}$ and R Engeln ${ }^{1}$ \\ ${ }^{1}$ Department of Applied Physics, Eindhoven University of Technology, P.O. Box 513, \\ 5600 MB Eindhoven, The Netherlands \\ 2 Leibniz Institute for Plasma Science and Technology, Felix-Hausdorff-Str. 2, \\ D-17489 Greifswald, Germany \\ ${ }^{3}$ Department of Chemistry, The Physical and Theoretical Chemistry Laboratory, \\ The University of Oxford, South Parks Road, Oxford, OX1 3QZ, UK \\ ${ }^{4}$ Helmholtz-Zentrum Berlin für Materialien und Energie, Kekuléstr. 5, 10489 Berlin, \\ Germany \\ E-mail: r.engeln@tue.nl
}

\begin{abstract}
A low pressure recombining Ar plasma to which mixtures of $\mathrm{N}_{2}$ and $\mathrm{O}_{2}$ were added has been studied to explore the relevance of surface related processes for the total chemistry. The abundances of the stable molecules $\mathrm{N}_{2}, \mathrm{O}_{2}, \mathrm{NO}, \mathrm{N}_{2} \mathrm{O}$ and $\mathrm{NO}_{2}$ have been measured by means of a combination of infrared tunable diode laser absorption spectroscopy and mass spectrometry.

A gas phase chemical kinetics model was developed in CHEMKIN to investigate the contribution of homogeneous interactions to the conversion of the feedstock gases $\mathrm{N}_{2}$ and $\mathrm{O}_{2}$. At a partial pressure of $\mathrm{N}_{2}$ plus $\mathrm{O}_{2}$ less than $8 \mathrm{~Pa}$, significant discrepancies between measured and calculated concentrations of $\mathrm{N}_{2} \mathrm{O}$ and $\mathrm{NO}_{2}$ were observed, indicating that heterogeneous processes are dominating the chemistry in this pressure range. At a partial pressure of $\mathrm{N}_{2}$ plus $\mathrm{O}_{2}$ higher than $40 \mathrm{~Pa}$ and a relatively high fraction of admixed $\mathrm{O}_{2}$ we observed a fair agreement between measured and calculated concentrations of NO molecules, indicating that homogeneous processes (notably Natom induced) are more dominant than heterogeneous processes.
\end{abstract}




\section{Introduction}

The interaction of reactive species, like atomic or molecular radicals, with a surface is a very general phenomenon. In plasma processing it is this interaction that leads to the modification of surfaces, i.e. deposition or etching [1-4]. In astro-chemistry it has been recognized that ice or dust particles in the interstellar space act as third body in association processes in which not only hydrogen molecules are formed, but also larger molecules [5]. In plasma assisted conversion of gases, the surfaces of a reactor also play an important role [6-8]. For example Gatilova et al [9] studied the formation of NO in a low pressure $\mathrm{N}_{2} / \mathrm{O}_{2}$ discharge. The authors focus mainly on the gas phase formation of NO, but recognize the importance of the surfaces of the plasma reactor. Castillo et al $[10,11]$ also conclude that mainly heterogeneous processes are responsible for the formation of NO.

In this paper the role of surface association reactions during the conversion of mixtures of $\mathrm{N}_{2}$ and $\mathrm{O}_{2}$ is in the centre of interest. Therefore a remote, recombining, low pressure argon plasma, produced by a cascaded arc (see also $[12,13]$ ) is used. This type of plasma exhibits a high dissociation efficiency. Furthermore, the contribution of excited particles to the total kinetics is low, because there is only convective power input into the plasma from the moment it expands from the cascaded arc into the reactor volume. In combination with the low working pressure, this creates a condition in which radical surface interactions can readily be addressed.

$\mathrm{N}_{2}$ and $\mathrm{O}_{2}$ molecules are admixed to the argon expansion and are dissociated via charge exchange and subsequent dissociative recombination mainly into atomic radicals. The resulting steady state mole fractions of the stable molecules in the system $\left(\mathrm{Ar}, \mathrm{N}_{2}\right.$, $\mathrm{O}_{2}, \mathrm{NO}, \mathrm{N}_{2} \mathrm{O}$ and $\mathrm{NO}_{2}$ ) are measured by means of a combination of mass spectrometry and tunable diode laser absorption spectroscopy.

The relative importance of homogeneous interactions with respect to heterogeneous interactions is expected to vary significantly with the surface to volume ratio of the reactor and the pressure in the reactor. The effect of the pressure is investigated in this paper. Typical gas phase reaction rates between a stable molecule and a radical are reported to be in the range of $10^{-18} \mathrm{~m}^{3} / \mathrm{s}$ (see the appendix). In general, the abundances of radicals in a plasma are orders of magnitude lower than the abundances of the stable molecules. When radical densities are a factor of $\simeq 10^{3}$ lower than the stable molecules, the gas phase reactions at a temperature of $1000 \mathrm{~K}$ can be expected to contribute to the chemistry at a partial pressure of $\mathrm{N}_{2}$ and $\mathrm{O}_{2}$ higher than $10 \mathrm{~Pa}$. At this pressure a significant fraction of the stable molecules can be converted by these reactions within $1 \mathrm{~s}$. The reaction rates of interactions between stable molecules are significantly lower, which implies that these types of interactions become dominant at even higher pressures. We will investigate the conversion of $\mathrm{N}_{2}$ and $\mathrm{O}_{2}$ at different partial pressures of $\mathrm{N}_{2}$ and $\mathrm{O}_{2}$ in the range of 1 - $40 \mathrm{~Pa}$ to find indications for a difference in conversion between mainly homogeneous interactions at high pressure and mainly heterogeneous interactions at low pressure. 


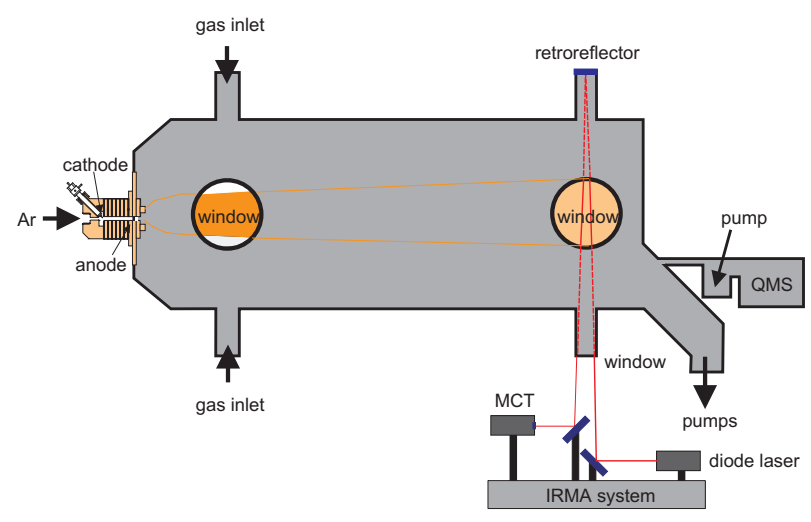

Figure 1. A sketch of the expanding thermal plasma setup with on the left the cascaded arc.

Furthermore, the behavior of the formation of $\mathrm{NO}$ at low admixed $\mathrm{O}_{2}$ fractions is scrutinised. For these conditions, a kind of threshold behavior in the formation of NO may be observed similar to the work of Nahorny et al [14] and Dilecce et al [15].

After a short introduction of the setup, the diagnostics and the expanding plasma in section 2, 3 and 4 respectively, the chemical model is presented in section 5 . The measurements of the molecular densities for different plasma conditions are discussed in section 6 and summarized in the last section.

\section{Experimental setup}

The setup, which is sketched in figure 1, has a cascaded arc as remote plasma source, which consists of a stack of four copper plates with a central bore $(\varnothing=4 \mathrm{~mm})$, through which the working gas (argon at a flow of 3000 standard cubic centimeters per minute, sccm) is directed. A discharge is maintained between cathode tip and anode plate, at a current setting between $I=45 \mathrm{~A}$ and $I=75 \mathrm{~A}$, which results in ionization of a significant fraction of the working gas: in case argon is used around $10-15 \%$ of the gas is ionized [16]. The copper plates are electrically insulated from each other, which stabilizes the discharge. During operation of the plasma source, the pressure in the arc channel is sub-atmospheric and in the relatively small volume of the arc channel $\left(0.3 \mathrm{~cm}^{3}\right)$, the power input can reach values up to $10 \mathrm{~kW}$. The mixture of atoms, ions and electrons flows through a nozzle and expands supersonically into the vessel. The stainless steel vessel has a diameter of $0.32 \mathrm{~m}$ and is $1.0 \mathrm{~m}$ long and is typically kept at a pressure of $p=20 \mathrm{~Pa}$ by a 3-stage pumping system. The pressure is monitored by three pressure sensors (a Baratron and two wide-range sensors), which are installed on top of the reactor. 
Table 1. The frequencies of the used absorption lines for the detection of $\mathrm{NO}, \mathrm{NO}_{2}$ and $\mathrm{N}_{2} \mathrm{O}$.

\begin{tabular}{cc}
\hline Molecule & Frequency $\left(\mathrm{cm}^{-1}\right)$ \\
\hline $\mathrm{NO}$ & 1884.3 \\
$\mathrm{NO}_{2}$ & 1600.9 \\
$\mathrm{~N}_{2} \mathrm{O}$ & 2203.7 \\
\hline
\end{tabular}

\section{Diagnostics}

A compact and transportable InfraRed Multicomponent Acquisition system (IRMA), which is based on mid-infrared absorption spectroscopy has been installed [17]. It contains four helium cooled independently tunable lead-salt diode lasers which can be temporally multiplexed. Rapid scan software with real-time line shape analysis provides simultaneous measurements of the absolute concentrations of several molecular species. In table 1 the types of molecules that are detected with this diagnostic are summarized, with the transition frequencies at which the analysis is performed.

The light beam of the diode lasers is directed through the plasma vessel twice via tubes that are directly connected to the vessel as sketched in figure 1 . This ensures that the composition of the background gas is determined, and the absorption path length is $1.62 \mathrm{~m}$. The laser light is directed to a mercury cadmium telluride detector (MCT, Graseby Infrared).

The instrumental broadening of the diode laser system is about $0.001 \mathrm{~cm}^{-1}$, and by scanning the temperature and current of the laser, a spectral range of approximately 100 $\mathrm{cm}^{-1}$ can be achieved. The laser light output power is in the order of several hundred $\mu \mathrm{W}$.

The HITRAN database [18] provides information on the line strengths, and by means of an advanced forward fitting implementation, the concentration is calculated real-time. The raw data of a typical absorption spectrum as a function of the laser current is shown in figure 2. Ramping the current through the laser diode at a constant operating temperature sweeps the laser frequency. A spectral region of approximately $1 \mathrm{~cm}^{-1}$ may be covered by means of an entire current ramp. One current ramp is performed in approximately $1 \mathrm{~ms}$. The time resolution that is achieved in the measurements presented in this paper, including the fitting procedure and averaging is $10 \mathrm{~ms}$.

In figure 2, in the range of one current ramp, absorption lines of both $\mathrm{NO}$ $\left(1884.3 \mathrm{~cm}^{-1}\right)$ and $\mathrm{H}_{2} \mathrm{O}\left(1884.6 \mathrm{~cm}^{-1}\right)$ in an $\mathrm{N}_{2} / \mathrm{O}_{2} / \mathrm{H}_{2}$ plasma can be recognized. The $\mathrm{H}_{2} \mathrm{O}$ absorption in a plasma reactor at low pressure is superimposed on a very broad absorption feature, caused by atmospheric $\mathrm{H}_{2} \mathrm{O}$. The spectral feature attributed to $\mathrm{NO}$ consists of more than 20 different transitions, and the ratio between the absorption lines changes with temperature. By a careful analysis of this ratio, the gas temperature can be estimated.

The integrated absorption of the spectral features is directly related to the 


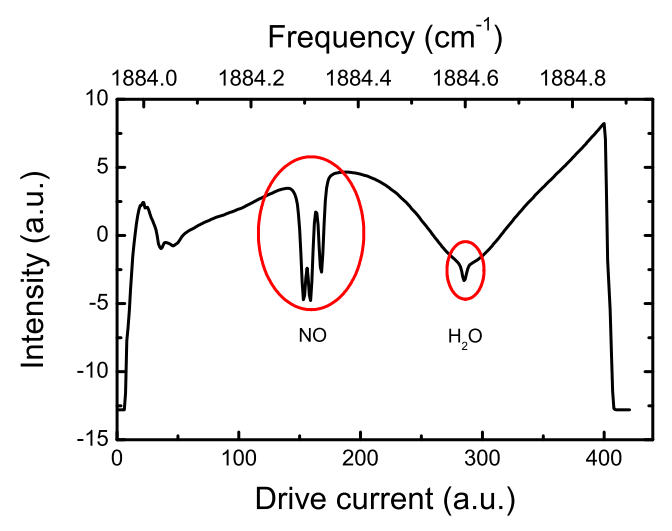

Figure 2. Absorption spectrum of a plasma containing a mixture of $\mathrm{N}_{2}, \mathrm{O}_{2}$ and $\mathrm{H}_{2}$. Clearly visible are the absorptions of $\mathrm{NO}$ and $\mathrm{H}_{2} \mathrm{O}$ in the vessel (narrow peak at around $1884.6 \mathrm{~cm}-1$ ) superimposed on the broad atmospheric water absorption.

concentration of the type of molecules under investigation. The spectral line intensities of the transitions serve as the scaling factor for the concentrations and are tabulated in the HITRAN database (2004 edition [18]).

The accuracy of the absorption measurements is mainly limited by uncertainties in the temperature profile over the path length of the laser light through the plasma reactor, and is typically $10 \%$. The mimimum detectable mole fractions vary for the different types of species. The minimum detectable absorption was about $10^{-3}$ which corresponds to a fractional detection limit down to $10^{-5}$ for the experiments and species described in this paper.

Also a quadrupole mass spectrometer (QMA 430, Balzers) with a secondary electron multiplier was installed at the beginning of the pump line and is thus probing the stable species $\left(\mathrm{Ar}, \mathrm{N}_{2}, \mathrm{O}_{2}, \mathrm{NO}, \mathrm{N}_{2} \mathrm{O}\right.$ and $\mathrm{NO}_{2}$ ) present in the vessel $[1,19]$. The minimum detectable mole fractions in the experiments described in this paper are in the order of $10^{-5}-10^{-4}$.

\section{Physical processes in the expanding plasma}

The argon plasma, which is created in the cascaded arc channel, expands supersonically into the vessel. Due to the fast expansion into the reactor, the gas temperature and the electron temperature drop rapidly. The gas temperature drops from approximately $5000 \mathrm{~K}(0.4 \mathrm{eV})$ at the start of the expansion, down to $450 \mathrm{~K}(0.04 \mathrm{eV})$ in the background of the reactor. The electron temperature reduces from $1 \mathrm{eV}$ at the start of the expansion down to $0.2 \mathrm{eV}$ downstream after the stationary shock.

The feedstock gases (mixtures of $\mathrm{N}_{2}$ and $\mathrm{O}_{2}$ ) are injected directly into the reactor and they mix efficiently with the expansion [20]. Due to the low electron temperature, direct electron-impact ionization or dissociation reactions are not efficient. In the expansion, the feedstock gases are dissociated by charge transfer and subsequent dissociative recombination mainly into atomic radicals. For example, the dissociation 


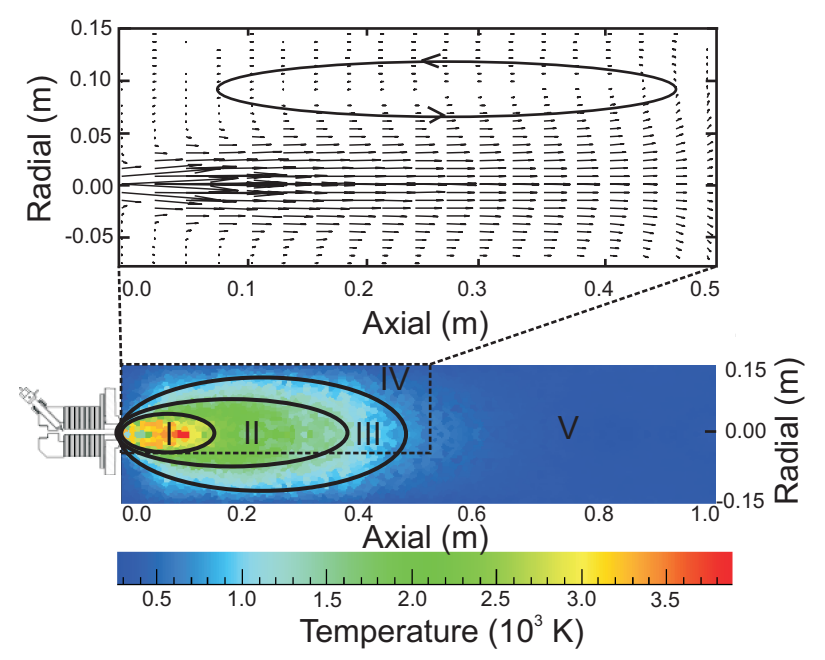

Figure 3. The calculated temperature distribution in the reactor and the division of the reactor into five different regions: I) the supersonic expansion, II) the subsonic expansion, III) the hot part of the background, IV) the cold background, including the walls of the reactor and $\mathrm{V}$ ) the background downstream in the reactor, where the measurements are performed. The calculated velocity profile of the first half of the reactor is also sketched. Note that the IR measurements are performed at an axial position of $0.8 \mathrm{~m}$.

of $\mathrm{N}_{2}$ molecules occurs via:

$$
\begin{aligned}
& \mathrm{Ar}^{+}+\mathrm{N}_{2} \rightarrow \mathrm{Ar}+\mathrm{N}_{2}^{+}, \\
& \mathrm{N}_{2}^{+}+\mathrm{e} \rightarrow \mathrm{N}+\mathrm{N}^{*},
\end{aligned}
$$

where $\mathrm{N}^{*}$ represents one of the two excited states $\left({ }^{2} \mathrm{P},{ }^{2} \mathrm{D}\right)$ of the $\mathrm{N}$ atom (see also [21]). An extra pathway of dissociating molecules in the reactor is via reactions with oxygen and nitrogen atomic radicals, e.g. $\mathrm{N}+\mathrm{NO} \rightarrow \mathrm{N}_{2}+\mathrm{O}$ and $\mathrm{N}+\mathrm{O}_{2} \rightarrow \mathrm{NO}+\mathrm{O}$. The radicals, produced in the expansion, flow through the reactor, and recombine before they are pumped away.

By means of a Direct Simulation Monte Carlo (DSMC, [22]), the flow pattern and temperature distribution are calculated. For a hot argon gas with an initial temperature of $5000 \mathrm{~K}$, expanding from the cascaded arc, the resulting temperature distribution in the reactor is shown in figure 3. Furthermore, the calculated flow pattern shows a strong recirculation cell in the reactor, that extends from the plasma source until halfway the reactor. The velocity profile is also sketched in the inset in figure 3. Our results are in good agreement with the results of Selezneva et al [23], who used a hybrid fluid-DSMC model.

In the results of the Monte Carlo simulation, five different parts can be discriminated, based on the calculated temperature distribution in the reactor. The rate of production of the various gas phase interactions that are possible between the species present in the reactor, depends strongly on the temperature. Therefore these parts of the reactor are considered separately in the analysis in this paper: I) the 


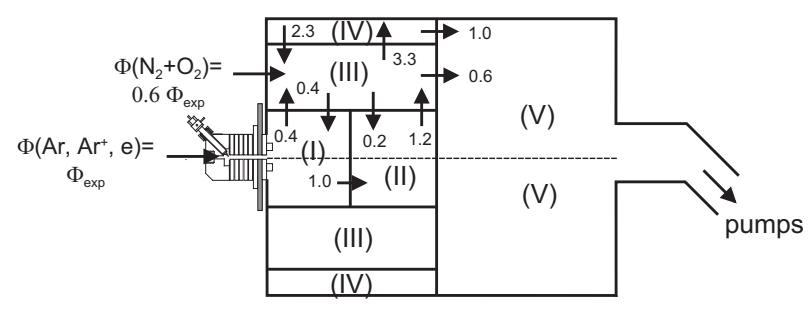

Figure 4. Sketch of the different parts of the reactor, together with the flows from each part into one of the other parts, normalized to the input flow through the cascaded arc.

supersonic expansion, including the stationary shock, where the feedstock gases mix efficiently with the expansion [20,24], II) the subsonic expansion, III) the hot part of the background, where the feedstock gases are injected into the reactor, IV) the cold part of the background and V) the part where the measurements are performed. In parts III and IV (part of the) recirculation cell is present. A fraction of the hot and cold background gases is directed towards part V. The division of the system into these five parts is sketched in figure 3 .

\section{CHEMKIN model}

A model has been developed for this plasma system, which is based on a combination of five zero-dimensional modules. For each part, the temperature, pressure, input flow, output flow and recirculation ratios are specified, based on the DSMC calculations. The solver of the commercial software package CHEMKIN [25] is used to perform the calculations involved.

Recycling of the species in the reactor between the different parts of the reactor influences the corresponding residence times. In figure 4, the different parts in the reactor are depicted, and the numbers denote the flow between them, normalized to the inlet flow of argon through the cascaded arc $(3000 \mathrm{sccm})$. The residence time $\tau_{\text {res }}$, temperature $T$ of the gas and the volume $V$ of each part, are given in table 2 for the flow settings used in the experiments that will be described in detail in section 6.1. The shock position, and thus the length of the supersonic expansion, varies between $3 \mathrm{~cm}$ at $3000 \mathrm{sccm}$ Ar and a background pressure of $p=100 \mathrm{~Pa}$ and $10 \mathrm{~cm}$ at $3000 \mathrm{sccm}$ Ar and a background pressure of $p=20 \mathrm{~Pa}$. Because the temperature in this region is high, and the flow of admixed gases in all studied cases is high, the residence time in part $\mathrm{I}$ is relatively low and the kinetics in this part are expected to play only a minor role compared to the total kinetics in the system. Variations in the size of the subsonic expansion are also believed to play only a minor role to the total kinetics in the system. Therefore the volumes of the different parts are kept equal for all studied pressures.

The set of chemical reactions involving molecules containing $\mathrm{N}$ and $\mathrm{O}$ atoms, is selected from Capitelli et al [26] and is supplemented with charge exchange and dissociative recombination reactions [27]. In the simulation program, we identified 17 
Table 2. The different regions in the reactor and the residence time in each region for the flow settings: $3000 \mathrm{sccm}$ Ar injected into part I and $1800 \mathrm{sccm} \mathrm{N}_{2}+\mathrm{O}_{2}$ injected into part III, at a pressure of $p=20 \mathrm{~Pa}$.

\begin{tabular}{ccccc}
\hline Region & Description & $\mathrm{T}(\mathrm{K})$ & $\mathrm{V}\left(\mathrm{m}^{3}\right)$ & $\tau_{\text {res }}(m s)$ \\
\hline I & supersonic expansion & 3000 & 0.001 & 0.26 \\
II & subsonic expansion & 2000 & 0.005 & 1.5 \\
III & hot background & 1200 & 0.02 & 3.3 \\
IV & cold background & 500 & 0.01 & 12 \\
V & measurement region & 500 & 0.04 & 51 \\
\hline
\end{tabular}

reactions contributing at least for a fraction of $10^{-3}$ to the production or destruction of the stable molecules present in the plasma. The reactions with their rate constants are summarized in the appendix.

In the simulations we do not explicitly take into account excited $\mathrm{N}$ atoms, although they are known to be produced by dissociative recombination via reaction 2 . These excited atoms are de-excited mainly by collisions with $\mathrm{NO}$ or $\mathrm{O}_{2}$ molecules, and as a result their lifetime is in the order of $10^{-4} \mathrm{~s}$ at a pressure of $\mathrm{p}=100 \mathrm{~Pa}$. Though, the rate of progress of $\mathrm{N}+\mathrm{O}_{2} \rightarrow \mathrm{NO}+\mathrm{O}$ is known to be significantly faster with excited $\mathrm{N}$ atoms than with $\mathrm{N}$ atoms in the ground state [28,29]. Therefore we implement a rate constant for this reaction which is a factor of five larger than reported by Capitelli et al $[26]$.

The starting conditions of the simulation can be summarized as:

(i) a fixed inflow of $2550 \mathrm{sccm} \mathrm{Ar}, 450 \mathrm{sccm} \mathrm{Ar}^{+}$and an equal flow of electrons from the cascaded arc into zone 1 (see also [16]),

(ii) the studied mixture of $\mathrm{N}_{2}$ and $\mathrm{O}_{2}$ is injected into zone 3 ,

(iii) the number of zero-dimensional plasma zones is determined from the DSMC calculations as described in the previous section, together with the temperature in each plasma zone and the flows between the different plasma zones.

\section{Results and discussion}

\subsection{Mixtures of $\mathrm{N}_{2}$ and $\mathrm{O}_{2}$ admixed to an Ar expansion}

A plasma expansion is created from a flow of $3000 \mathrm{sccm}$ argon in the cascaded arc. A total power of $5 \mathrm{~kW}\left(I_{\mathrm{arc}}=75 \mathrm{~A}\right)$ is used to create an Ar plasma in the arc channel. This plasma expands from the exit of the arc channel into the reactor, which is kept at a background pressure of $p_{\mathrm{bg}}=20 \mathrm{~Pa}$ or $p_{\mathrm{bg}}=100 \mathrm{~Pa}$. A total flow of $1800 \mathrm{sccm}$ of mixtures of $\mathrm{N}_{2}$ and $\mathrm{O}_{2}$ is injected directly into the reactor. Based on the flow settings of the filling gases, the sum of the partial pressures of $\mathrm{N}_{2}$ and $\mathrm{O}_{2}$ amounts to $p_{\mathrm{N}_{2}+\mathrm{O}_{2}}=38 \mathrm{~Pa}$ at a background pressure $p_{\mathrm{bg}}=100 \mathrm{~Pa}$ and $p_{\mathrm{N}_{2}+\mathrm{O}_{2}}=7.6 \mathrm{~Pa}$ at $p_{\mathrm{bg}}=20 \mathrm{~Pa}$.

The molecular abundances of the species formed in the plasma vessel are investigated as function of the ratio of admixed $\mathrm{O}_{2}$ flow over the total flow of $\mathrm{O}_{2}$ and $\mathrm{N}_{2}$. 
The measurements are presented for two different pressures, to investigate the possible influence of heterogeneous processes.

In figure 5 , the measured mole fractions of $\mathrm{Ar}, \mathrm{N}_{2}, \mathrm{O}_{2}, \mathrm{NO}, \mathrm{N}_{2} \mathrm{O}$ and $\mathrm{NO}_{2}$ are plotted on a semi-logarithmic scale. All the species are measured with the quadrupole mass spectrometer. Furthermore, $\mathrm{NO}$ and $\mathrm{N}_{2} \mathrm{O}$ are measured by infrared absorption spectroscopy, which provides direct in-situ results. The results for $\mathrm{NO}$ and $\mathrm{N}_{2} \mathrm{O}$ from mass spectroscopy and tunable diode laser absorption spectroscopy measurements showed good agreement: within $10 \%$.

At both background pressures in which experiments have been performed the molecules $\mathrm{N}_{2}$ and $\mathrm{O}_{2}$ were dominantly present (cf. Figure 5 and 6 ). The abundances of the other types of molecules ( $\mathrm{NO}, \mathrm{NO}_{2}$ and $\mathrm{N}_{2} \mathrm{O}$ ) are one to three orders of magnitude lower. Remarkable is the maximum abundance of NO: it is independent of pressure and reaches a fraction of $10^{-2}$ of the total pressure (see also [30]). Contrary to NO, the abundance of $\mathrm{N}_{2} \mathrm{O}$ and $\mathrm{NO}_{2}$ decreases significantly with an increase of pressure.

\subsection{Simulated volume interactions}

In figure 6 , the measured mole fractions of $\mathrm{Ar}, \mathrm{N}_{2}, \mathrm{O}_{2}, \mathrm{NO}, \mathrm{N}_{2} \mathrm{O}$ and $\mathrm{NO}_{2}$ are plotted for the same conditions as presented in figure 5(a) and 5(b). The results of the complementary Chemkin calculations, in which only gas phase (homogeneous) interactions are taken into account, are also shown in figure 6. The abundances of $\mathrm{Ar}$ and $\mathrm{N}_{2}$ are reproduced by the model. The calculated mole fraction of $\mathrm{O}_{2}$ is lower than the measured one at all flow ratios. The main reason is the absence of an effective volume loss channel for $\mathrm{O}$ atoms in the model. This leads to an unrealistically high calculated oxygen atom abundance in the reactor, up to a mole fraction of $6 \times 10^{-2}$. The model also predicts that a small amount of NO is formed in the gas phase, especially at high fractions of admixed $\mathrm{O}_{2}$. However, the trend of the calculated density as function of the flow ratio does not agree with the measured trend. And for low oxygen flows the calculated NO mole fractions are orders of magnitude lower than the measured ones. The abundances of the molecules $\mathrm{N}_{2} \mathrm{O}$ and $\mathrm{NO}_{2}$ are calculated to be smaller than $10^{-8}$, which is several orders of magnitude lower than measured.

It is clear that for both series of measurements presented in figure 6, significant discrepancies between calculated and measured mole fractions are observed. Since not only the trends but also the absolute values of the mole fractions are not in agreement with the results of the CHEMKIN model in which only homogeneous interactions are taken into account, we conclude that heterogeneous interactions play an important role in the conversion of $\mathrm{N}_{2}$ and $\mathrm{O}_{2}$.

\subsection{Threshold behavior of NO production}

In figure 5(b), we observe a threshold behavior in the formation of NO for relatively low admixed $\mathrm{O}_{2}$ fractions: the NO mole fraction becomes only significant for an admixed $\mathrm{O}_{2}$ fraction higher than $10 \%$. This effect is also observed in for example the work of 

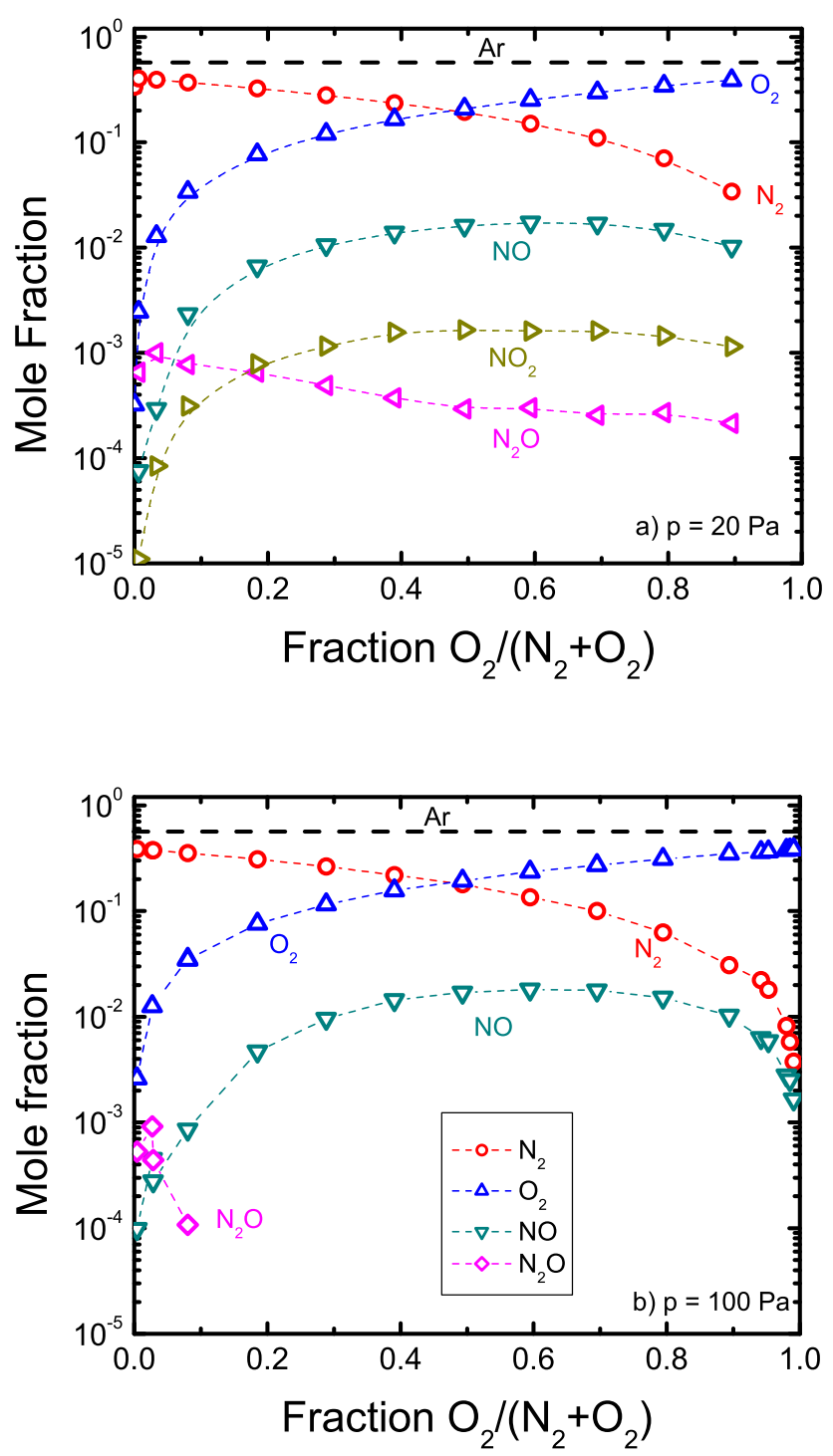

Figure 5. The measured mole fraction of the molecules in the plasma as a function of the flow ratio of $\mathrm{O}_{2}$ over the total flow of the injected gas mixture of $\mathrm{N}_{2}$ and $\mathrm{O}_{2}$. A flow of $3000 \mathrm{sccm}$ argon is injected through the cascaded arc into the reactor, and a flow of $1800 \mathrm{sccm}$ of the injected gas mixture of $\mathrm{N}_{2}$ and $\mathrm{O}_{2}$ is injected directly into the reactor. The results are given for a) $p=20 \mathrm{~Pa}$ and b) $p=100 \mathrm{~Pa}$. The lines through the measured points serve only as a guide to the eye.

Nahorny et al [14] and Dilecce et al [15]. To investigate this threshold behavior in our system in more detail, the effective fraction of NO is presented as a function of the admixed fraction of $\mathrm{O}_{2}$. The effective fraction represents the mole fraction, based on all the types of species in the reactor, except argon. It is calculated by multiplying the measured mole fraction of NO by the ratio of the total injected flows and the admixed flows of $\mathrm{N}_{2}$ and $\mathrm{O}_{2}$.

In figure 7 , the effective mole fractions are plotted for three different pressures: 

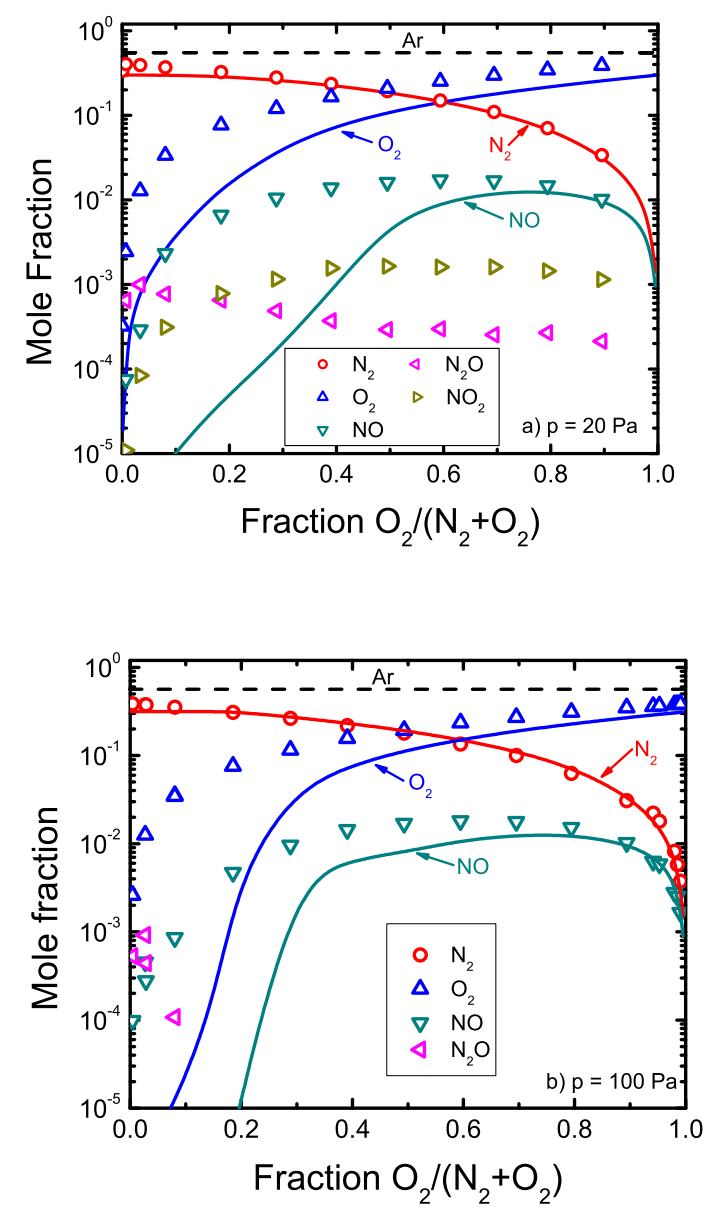

Figure 6. The mole fraction of the measured molecules in the plasma (symbols) as function of the flow ratio of $\mathrm{O}_{2}$ over the total flow of the injected gas mixture of $\mathrm{N}_{2}$ and $\mathrm{O}_{2}$. A flow of $3000 \mathrm{sccm}$ argon is injected through the cascaded arc into the reactor, and a flow of $1800 \mathrm{sccm}$ of the injected gas mixture of $\mathrm{N}_{2}$ and $\mathrm{O}_{2}$ is injected directly into the reactor. The lines indicate the calculated mole fractions of $\mathrm{Ar}, \mathrm{N}_{2}, \mathrm{O}_{2}$ and NO based on purely homegeneous interactions. The results are given for a) $p=20 \mathrm{~Pa}$ and b) $p=100 \mathrm{~Pa}$.

$p=9,20$ and $100 \mathrm{~Pa}$. To achieve the lowest pressure, i.e. $\mathrm{p}=9 \mathrm{~Pa}$, the total flow of $\mathrm{Ar}$, $\mathrm{N}_{2}$ and $\mathrm{O}_{2}$ was decreased by a factor of two, to $2400 \mathrm{sccm}$, which resulted in a partial pressure of the injected $\mathrm{N}_{2}$ and $\mathrm{O}_{2}$ of $3 \mathrm{~Pa}$.

The threshold behavior becomes more pronounced for higher pressures. At higher pressures, gas phase interactions will influence the plasma chemistry more than heterogeneous interactions. The pressure dependence of this threshold suggests that heterogeneous interactions are responsible for cancelling the threshold effect.

The results of the previous calculations in which only homogeneous reactions are taken into account (see figure 6), seem to underpin this reasoning. A clear threshold behavior can be observed in figure 6. However, the admixed $\mathrm{O}_{2}$ fraction at which 


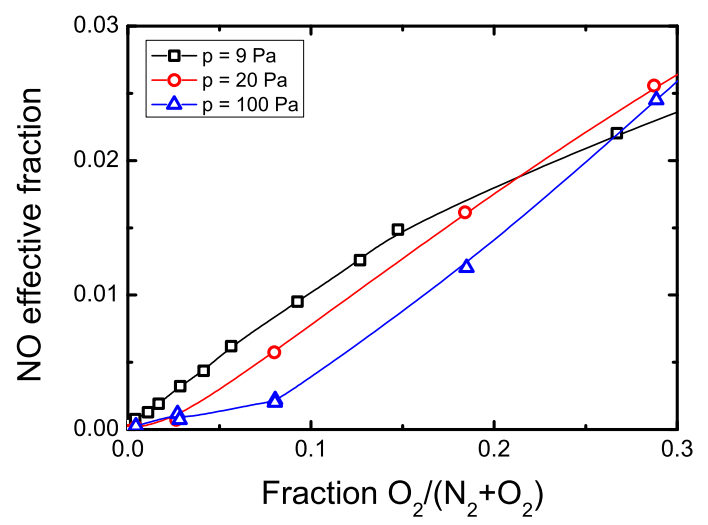

Figure 7. Threshold behavior of $\mathrm{NO}$ for low admixed $\mathrm{O}_{2}$ flows. For three pressures, the NO effective fraction is plotted as a function of the admixed $\mathrm{O}_{2}$. The effective fraction is the mole fraction, not taking into account argon, see the text for details. For $p=20 \mathrm{~Pa}$ and $p=100 \mathrm{~Pa}$, a flow of $3000 \mathrm{sccm}$ Ar and $1800 \mathrm{sccm}$ of mixtures of $\mathrm{N}_{2}$ and $\mathrm{O}_{2}$ are admixed. For $p=9 \mathrm{~Pa}$, the total flow was decreased by a factor of two.

the mole fraction of NO starts to increase drastically, is much higher than during the measurements (see figure 7).

For $p=20 \mathrm{~Pa}$, the NO mole fraction is smaller than $10^{-5}$ for admixed $\mathrm{O}_{2}$ fractions up to 0.10 , and for $p=100 \mathrm{~Pa}$ for admixed $\mathrm{O}_{2}$ fractions up to 0.20 . This shift to higher admixed $\mathrm{O}_{2}$ fractions may be explained by an overestimated $\mathrm{N}$ atom density in the calculations (not plotted). In the calculations presented in figure 6 , the $\mathrm{N}$ atom density for the conditions at low admixed $\mathrm{O}_{2}$ fractions, is high compared to the $\mathrm{O}_{2}$ density. In that case $\mathrm{NO}$ is produced through $\mathrm{N}+\mathrm{O}_{2} \rightarrow \mathrm{NO}+\mathrm{O}$, but the high abundance of $\mathrm{N}$ atoms results in the immediate destruction of $\mathrm{NO}$ via $\mathrm{N}+\mathrm{NO} \rightarrow \mathrm{N}_{2}+\mathrm{O}$. In the gas phase simulations, the destruction of NO proceeds too fast to explain the measured NO abundance. Since heterogeneous processes are not taken into account in the calculations, the loss of $\mathrm{N}$ atoms is highly underestimated. Consequently, the density of $\mathrm{N}$ atoms is considerably overestimated and so is the destruction rate for NO. Including heterogeneous processes in the calculations will reduce the pronounced threshold effect that appears in the gas phase model. The implementation of heterogeneous processes in the model will be treated in detail in our next paper.

\subsection{Molecule formation at low effective pressure}

To be able to distinguish even more between the effects of heterogeneous and homegeneous processes, we also performed measurements on mixtures of $\mathrm{N}_{2}$ and $\mathrm{O}_{2}$ at a low effective pressure. In this case, the follow-up reactions in the volume of the reactor between surface produced species and radicals in the gas phase should be less significant with respect to the total kinetics in the plasma.

Mixtures of $\mathrm{N}_{2}$ and $\mathrm{O}_{2}$ were admixed to an argon/helium expansion at a pressure of 


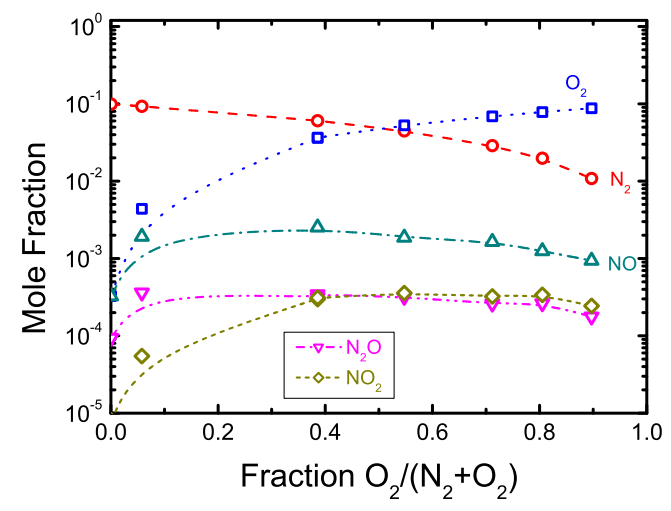

Figure 8. The measured molecular abundances in the plasma created from Ar/He: $300 / 1500 \mathrm{sccm}$, to which mixtures of $\mathrm{N}_{2}+\mathrm{O}_{2}$ are admixed, where the total flow of $\mathrm{N}_{2}$ and $\mathrm{O}_{2}$ is $200 \mathrm{sccm}$. The pressure is set to $p=6 \mathrm{~Pa}$ and the current through the cascaded arc channel $\mathrm{I}=75 \mathrm{~A}$.

$p=6 \mathrm{~Pa}$. Since a relatively large amount of He was admixed, the diffusion of particles in the plasma towards the walls of the reactor proceeded faster because of the relatively low mass of He atoms. Furthermore, the partial pressure of the molecules of interest was significantly lower than in the experiments described in the previous section. This implies that the follow-up reactions between surface produced molecules and radicals is less important.

A combination of $300 \mathrm{sccm}$ Ar and $1500 \mathrm{sccm}$ He is directed through the arc. A total flow of $200 \mathrm{sccm} \mathrm{N} \mathrm{N}_{2}+\mathrm{O}_{2}$ is injected into the background of the reactor and mixes with the $\mathrm{Ar} / \mathrm{He}$ expansion. The fraction of admixed $\mathrm{O}_{2}$ of the total admixed $\mathrm{O}_{2}$ and $\mathrm{N}_{2}$ flow is varied from zero, i.e. pure $\mathrm{N}_{2}$ flow, to one, i.e. pure $\mathrm{O}_{2}$ flow. The pressure in the reactor is kept at $p=6 \mathrm{~Pa}$ and if the admixed gases mix perfectly with the expansion, the total flow of $\mathrm{N}_{2}$ and $\mathrm{O}_{2}$ can entirely be dissociated in the expansion by charge exchange and subsequent dissociative recombination. At these flow settings, $p_{\mathrm{N}_{2}+\mathrm{O}_{2}}=1 \mathrm{~Pa}$, which is a factor of 40 lower than in the experiments performed at $p=100 \mathrm{~Pa}$ as displayed in figure 6(b).

The mole fraction of the measured types of molecules is given in figure 8. Also in this experiment, mainly $\mathrm{N}_{2}$ and $\mathrm{O}_{2}$ are observed. The abundances of the other types of molecules ( $\mathrm{NO}, \mathrm{N}_{2} \mathrm{O}$ and $\mathrm{NO}_{2}$ ) are two to three orders of magnitude lower than the abundances of $\mathrm{N}_{2}$ and $\mathrm{O}_{2}$. Only for admixed $\mathrm{O}_{2}$ fractions higher than 0.7 , the observed ratio between the abundance of $\mathrm{NO}$ and $\mathrm{N}_{2}$ is comparable to the measurements at higher pressures. For this range of high $\mathrm{O}_{2}$ partial pressures homogeneous reactions can explain the observed behavior even at these low pressures.

The ratios between the abundances of $\mathrm{NO}_{2}$ to $\mathrm{NO}$ and $\mathrm{N}_{2} \mathrm{O}$ to $\mathrm{NO}$ are higher than in figure 5. This indicates faster formation rates or slower destruction rates of $\mathrm{N}_{2} \mathrm{O}$ and $\mathrm{NO}_{2}$. At this point we cannot discriminate between these two effects. It is very likely that heterogeneous effects play a role, because in our gas phase simulations we do not 
observe significant production of $\mathrm{NO}_{2}$ and $\mathrm{N}_{2} \mathrm{O}$ for low admixed fractions of $\mathrm{O}_{2}$, whereas the measured abundances of $\mathrm{N}_{2} \mathrm{O}$ and $\mathrm{NO}_{2}$ seem to increase at lower pressures.

Furthermore, the threshold behavior in NO is absent at this low effective pressure. This is consistent with the results from the previous section, where the threshold behavior was most pronounced at the highest studied pressures.

\section{Conclusions}

To explore the contribution of surface related processes to the total kinetics in a low pressure recombining plasma, we measured the abundances of the stable molecules in $\mathrm{N}_{2} / \mathrm{O}_{2}$ containing discharges for a variety of conditions by means of mass spectrometry and tunable diode laser absorption spectroscopy. A simulation has been developed in CHEMKIN, that takes into account the gas phase chemistry.

The homogeneous interactions can explain the measured abundances of the stable molecules reasonably well for total partial pressures of $\mathrm{N}_{2}$ and $\mathrm{O}_{2}$ higher than $38 \mathrm{~Pa}$ and for a relatively high admixture of $\mathrm{O}_{2}$. For lower total partial pressures, significant deviations arise between measured and simulated gas composition. Extra loss channels for $\mathrm{O}$ and $\mathrm{N}$ atoms should be introduced, especially for admixed $\mathrm{O}_{2}$ fractions lower than 0.2 , most likely in the form of heterogeneous interactions. An extra loss channel for $\mathrm{O}$ atoms would increase the calculated $\mathrm{O}_{2}$ density. An extra loss channel for $\mathrm{N}$ atoms reduces the predicted threshold effect for NO.

In our next paper we describe the development of a module in CHEMKIN that takes heterogeneous interactions (surface adsorbption, surface desorption, Ely-Rideal, Langmuir-Hinshelwood and recirculation of surface-produced species into the plasma volume) into account and we investigate, quantitatively, the contributions of these interactions to the overall plasma chemistry. 


\section{Appendix: gas phase reactions}

Here, a summary of the implemented gas phase interactions is given. The reaction rate constants are obtained from Capitelli et al [26]. The rate constants are presented by means of their Arrhenius parameters, as in:

$$
k=A T^{n} \exp \left(-\frac{e \hat{E}_{\mathrm{act}}}{k T}\right),
$$

where $A$ is the prefactor, $n$ the temperature exponent and $\hat{E}_{\text {act }}$ the activation energy, expressed in $\mathrm{eV}$.

\begin{tabular}{rrrrr}
\hline & reaction & $\mathrm{A}\left(\mathrm{m}^{3} / \mathrm{s}\right)$ & $\mathrm{n}$ & $\hat{E}_{\text {act }}(\mathrm{eV})$ \\
\hline & $\mathrm{Ar}^{+}+\mathrm{N}_{2} \rightarrow \mathrm{N}_{2}^{+}+\mathrm{Ar}$ & $2.00 \mathrm{E}-16$ & 0 & 0 \\
2 & $\mathrm{Ar}^{+}+\mathrm{O}_{2} \rightarrow \mathrm{O}_{2}^{+}+\mathrm{Ar}$ & $1.00 \mathrm{E}-16$ & 0 & 0 \\
3 & $\mathrm{Ar}^{+}+\mathrm{NO} \rightarrow \mathrm{NO}^{+}+\mathrm{Ar}$ & $3.00 \mathrm{E}-16$ & 0 & 0 \\
4 & $\mathrm{~N}_{2}^{+}+\mathrm{E} \rightarrow 2 \mathrm{~N}$ & $2.00 \mathrm{E}-13$ & 0 & 0 \\
5 & $\mathrm{O}_{2}^{+}+\mathrm{E} \rightarrow 2 \mathrm{O}$ & $2.00 \mathrm{E}-13$ & 0 & 0 \\
6 & $\mathrm{NO}+\mathrm{E} \rightarrow \mathrm{N}+\mathrm{O}$ & $2.00 \mathrm{E}-13$ & 0 & 0 \\
7 & $\mathrm{~N}+\mathrm{NO} \rightarrow \mathrm{O}+\mathrm{N}_{2}$ & $1.00 \mathrm{E}-18$ & 0.5 & 0 \\
8 & $\mathrm{~N}+\mathrm{O}_{2} \rightarrow \mathrm{O}+\mathrm{NO}$ & $5.50 \mathrm{E}-20$ & 1 & 0.27 \\
9 & $\mathrm{~N}+\mathrm{NO}_{2} \rightarrow 2 \mathrm{O}+\mathrm{N}_{2}$ & $9.10 \mathrm{E}-19$ & 0 & 0 \\
10 & $\mathrm{~N}+\mathrm{NO}_{2} \rightarrow \mathrm{O}+\mathrm{N}_{2} \mathrm{O}$ & $3.00 \mathrm{E}-18$ & 0 & 0 \\
11 & $\mathrm{~N}+\mathrm{NO}_{2} \rightarrow \mathrm{N}_{2}+\mathrm{O}_{2}$ & $7.00 \mathrm{E}-19$ & 0 & 0 \\
12 & $\mathrm{~N}+\mathrm{NO}_{2} \rightarrow 2 \mathrm{NO}$ & $2.30 \mathrm{E}-18$ & 0 & 0 \\
13 & $\mathrm{O}+\mathrm{N}_{2} \mathrm{O} \rightarrow \mathrm{N}_{2}+\mathrm{O}_{2}$ & $8.30 \mathrm{E}-18$ & 0 & 1.21 \\
14 & $\mathrm{O}+\mathrm{N}_{2} \mathrm{O} \rightarrow \mathrm{NO}+\mathrm{NO}_{1}$ & $1.50 \mathrm{E}-16$ & 0 & 1.22 \\
15 & $\mathrm{O}+\mathrm{NO}_{2} \rightarrow \mathrm{NO}+\mathrm{O}_{2}$ & $3.30 \mathrm{E}-18$ & 0.2 & 0 \\
& & & & \\
16 & $\mathrm{NO}+\mathrm{O}_{2} \rightarrow \mathrm{O}+\mathrm{NO}_{2}$ & $2.80 \mathrm{E}-18$ & 0 & 2.02 \\
17 & $\mathrm{NO}+\mathrm{N}_{2} \mathrm{O} \rightarrow \mathrm{N}_{2}+\mathrm{NO}_{2}$ & $4.60 \mathrm{E}-16$ & 0 & 2.17 \\
\hline
\end{tabular}




\section{References}

[1] M. C. M. van de Sanden, R. J. Severens, W. M. M. Kessels, R. F. G. Meulenbroeks, and D. C. Schram. Plasma chemistry aspects of a-Si:H deposition using an expanding thermal plasma. J. Appl. Phys., 84(5):2426-2435, 1998.

[2] L. Martinu and D. Poitras. Plasma deposition of optical films and coatings: a review. J. Vac. Sci. Technol. A, 18(6):2619-2645, 2000.

[3] J. Benedikt, R. V. Woen, S. L. M. van Mensfoort, V. Perina, and M. C. M. van de Sanden. Plasma chemistry during the deposition of a-C:H films and its influence on film properties. Diamond and related materials, 12:90-97, 2003.

[4] R. Förch, Z. Zhan, and K. Wolfgang. Soft plasma treated surfaces: Tailoring of structure and properties for biomaterial applications. Plasma Process. Polym., 2(5):351-372, 2005.

[5] G. Vidali, J. E. Roser, L. Ling, E. Congiu, G. Manicó, and V. Pirronello. The formation of interstellar molecules via reactions on dust grain surfaces. Faraday Discuss., 133:125-135, 2006.

[6] S. Tanaka, H. Uyama, and O. Matsumoto. Synergistic effects of catalysts and plasmas on the synthesis of ammonia and hydrazine. Plasma Chemistry and Plasma Processing, 14(4):491-504, 1994.

[7] H. Kim. Nonthermal plasma processing for air-pollution control: A historical review, current issues, and future prospects. Plasma Process. Polym., 1:91-110, 2004.

[8] A. Rousseau, A. V. Meshchanov, and J. Röpcke. Evidence of plasma-catalyst synergy in a lowpressure discharge. Appl. Phys. Lett., 88:021503, 2006.

[9] L. V. Gatilova, K. Allegraud, J. Guillon, Y. Z. Ionikh, G. Cartry, J. Röpcke, and A. Rousseau. NO formation mechanisms studied by infrared laser absorption in a single low-pressure plasma pulse. Plasma Sources Sci. Technol., 16:S107-S114, 2007.

[10] M. Castillo, V. J. Herrero, I. Méndez, and I. Tanarro. Spectrometric and kinetic study of a modulated glow air discharge. Plasma Sources Sci. Technol., 13:343-350, 2004.

[11] M. Castillo, I. Mendez, A. M. Islyaikin, V. J. Herrero, and I. Tanarro. Low-pressure dc air plasmas. investigation of neutral and ion chemistry. J. Phys. Chem. A, 109:6255-6263, 2005.

[12] G. J. H. Brussaard, K. G. Y. Letourneur, M. Schaepkens, M. C. M. van de Sanden, and D. C. Schram. Stripping of photoresist using a remote thermal $\mathrm{Ar} / \mathrm{O}_{2}$ and $\mathrm{Ar} / \mathrm{N}_{2} / \mathrm{O}_{2}$ plasma. J. Vac. Sci. Technol. B, 21(1):61-66, 2003.

[13] M. F. A. M. van Hest, J. R. Haartsen, M. H. M. van Weert, D. C. Schram, and M. C. M. van de Sanden. Analysis of the expanding thermal argon-oxygen plasma gas phase. Plasma Sources Sci. Technol., 12:539-553, 2003.

[14] J. Nahorny, C. M. Ferreira, B. Gordiets, D. Pagnon, M. Touzeau, and M. Vialle. Experimental and theoretical investigation of a $\mathrm{N}_{2}-\mathrm{O}_{2}$ DC flowing glow discharge. J. Phys. D: Appl. Phys., 28:738, 1995.

[15] G. Dilecce and S. De Benedictis. Experimental studies on elementary kinetics in $\mathrm{N}_{2}-\mathrm{O}_{2}$ pulsed discharges. Plasma Sources Sci. Technol., 8:266, 1999.

[16] M. C. M. van de Sanden, J. M. de Regt, and D. C. Schram. The behaviour of heavy particles in the expanding plasma jet in argon. Plasma Sources Sci. Technol., 3:501-510, 1994.

[17] J. Röpcke, L. Mechold, M. Käning, J. Anders, G. Wienhold, D. Nelson, and M. Zahniser. IRMA: A tunable infrared multicomponent acquisition system for plasma diagnostics. Rev. Sci. Instrum., 71(10):3706-3710, 2000.

[18] L. S. Rothman, D. Jacquemart, A. Barbe, D. C. Benner, M. Birk, L. R. Brown, M. R. Carleer, C. Chackerian Jr., K. Chance, L. H. Coudert, V. Dana, V. M. Devi, J. M. Flaud, R. R. Gamache, A. Goldman, J. M. Hartmann, K. W. Jucks, A. G. Maki, J. Y. Mandin, S. T. Massie, J. Orphal, A. Perrin, C. P. Rinsland, M. A. H. Smith, J. Tennyson, R. N. Tolchenov, R. A. Toth, J. V. Auwera, P. Varanasi, and G. Wagner. The HITRAN 2004 molecular spectroscopic database. Journal of quantitative spectroscopy \& radiative transfer, 96:139-204, 2005.

[19] M. F. A. M. van Hest, A. de Graaf, M. C. M. van de Sanden, and D. C. Schram. Use of in 
situ FTIR spectroscopy and mass spectrometry in an expanding hydrocarbon plasma. Plasma Sources Sci. Technol., 9:615-624, 2000.

[20] P. Vankan, S. Mazouffre, R. Engeln, and D. C. Schram. Inflow and shock formation in supersonic, rarefied plasma expansions. Phys. Plasmas, 12:102303, 2005.

[21] D. C. Schram. Plasma processing and chemistry. Pure Appl. Chem., 74(3):369-380, 2002.

[22] G. A. Bird. Proc. 24th Int. Symp. on Rarefied Gas Dynamics, Monopoly (Bari), page 541, 2004.

[23] S. E. Selezneva, M. I. Boulos, M. C. M. van de Sanden, R. Engeln, and D. C. Schram. Stationary supersonic plasma expansion: continuum fluid mechanics versus direct simulation Monte Carlo method. J. Phys. D: Appl. Phys., 35:1362-1372, 2002.

[24] O Gabriel, P G J Colsters, D C Schram, and R Engeln. Two-dimensional flow characteristic of a hot expanding plasma. Plasma Sources Sci. Technol., 17(1):015011 (8pp), 2008.

[25] Reaction Design. CHEMKIN(R) Interface 4. Simulation software, 2004.

[26] M. Capitelli, C. M. Ferreira, B. F. Gordiets, and A. I. Osipov. Plasma kinetics in atmospheric gases. Springer-Verlag Berlin Heidelberg New York, 2000.

[27] J. H. van Helden. The generation of molecules through plasma-surface interactions. PhD thesis, Technische Universiteit Eindhoven, 2006.

[28] M. Gonzalez, I. Miquel, and R. Sayos. VTST kinetics study of the $\mathrm{N}\left({ }^{2} \mathrm{D}\right)+\mathrm{O}_{2}\left(\mathrm{X}^{3} \Sigma_{\mathrm{g}}^{-}\right) \rightarrow \mathrm{NO}\left(\mathrm{X}^{2} \Pi\right)+\mathrm{O}\left({ }^{3} \mathrm{P},{ }^{1} \mathrm{D}\right)$ reactions based on CASSCF and CASPT2 ab initio calculations including excited potential energy surfaces. Chem. Phys. Lett., 335:339-347, 2001.

[29] I. A. Kossyi, A. Y. Kostinksy, A. A. Matveyev, and V. P. Silakov. Kinetic scheme of the nonequilibrium discharge in nitrogen-oxygen mixtures. Plasma Sources Sci. Technol., 1:207-220, 1992.

[30] J. H. van Helden, R. A. B. Zijlmans, D. C. Schram, and R. Engeln. Resemblance in gas composition of Ar- $\mathrm{N}_{2}-\mathrm{O}_{2}$ and Ar-NO plasmas. Plasma Sources Sci. Technol., 18:025020, 2009. 